\title{
Breast Cancer in West Java: Where Do We Stand and Go?
}

\author{
Yohana Azhar ${ }^{1}$, Hasrayati Agustina ${ }^{2}$, Maman Abdurachman ${ }^{1}$, Dimyati Achmad ${ }^{1}$ \\ ${ }^{1}$ Department of Surgery, Oncology Division, Hasan Sadikin General Hospital, Universitas Padjajaran, Bandung, West Java, Indonesia \\ ${ }^{2}$ Department of Anatomical Pathology, Hasan Sadikin General Hospital, Universitas Padjajaran, Bandung, West Java, Indonesia
}

\section{ARTICLE INFO}

Received : 15 April 2020

Reviewed : 05 May 2020

Accepted : 09 July 2020

Keywords:

breast cancer, regional breast cancer registry system, West Java

\begin{abstract}
Background: Breast cancer is the most common cancer in Indonesia, a low-middle income country in Southeast Asia. We provide a regional hospital-based cancer registry of the central hospital in West Java, Indonesia. This study aims to characterize the presentation, diagnosis, evaluation, and management of breast cancer; to develop a regional breast cancer registry in West Java to monitor cancer care patterns; to evaluate cancer treatment outcomes.
\end{abstract}

Methods: The data were collected from the medical records deposited in the Hasan Sadikin General Hospital Information System. The team has been contracted to operate the registry \& organize an advisory board to standardize definitions of coding terminology of the registry's reporting system and to monitor the cancer care pattern. Data validation was conducted by a team in the cancer registry, consisting of health officers, pathologists, and registrars. Data management and analysis were conducted by the cancer registry team.

Results: A total of 913 women diagnosed with breast cancer, from January 2014 until December 2018 , were studied. The median age was 49.5 years old. The initial diagnosis was at the age of 42.4 years old on average. About $64.5 \%$ were diagnosed with stage- 3 and -4 cancers, and $75.1 \%$ had undergone a mastectomy, of which $47.3 \%$ of the intent was palliative. Of those who have hormonal receptors, only $26.9 \%$ were positive, and $36.5 \%$ were not assessed for immunohistochemistry evaluation. Inappropriate surgical management of breast cancer was common at the community level, which included indiscriminate diagnostic lumpectomy (21.9\%), incomplete mastectomy and omission, or suboptimal lymph node axillary clearance (47.4\%). Only $3.0 \%$ of patients received breast-conserving surgery and were treated with mastectomy and reconstruction.

Conclusions: Breast cancer in West Java is often recognized at the late stage. Treatment was suboptimal, leading to poor survival. A more aggressive approach to early detection and treatment needs to be developed to improve the outcomes of this potentially curable disease.

\section{INTRODUCTION}

Breast cancer is the highest and the major burdensome disease to individuals and society. In West Java Indonesia, breast cancer has been a leading case of female cancer since 2010 based on pathological registration in Indonesia. The incidence of breast cancer in Indonesia has significantly increased over the last decade. In 2012, 17,792 new breast cancer patients were reported and the aged standard in the incidence rate of female breast cancer was 48.9 per 100,000 [1].

West Java has the largest population in Indonesia and embraces the Sundanese culture. Sundanese is the mother tongue passed for many generations and, thus, becomes the main language amongst West Java people. However, many ethnic groups have become coexist and enrich society recently. There is probably an indication that this unique ethnic group might have a strong influence in the presence of risk factors, breast cancer screening utilization, stages of the disease, and availability of appropriate care.

Based on the 2017 population census, there were approximately 48 million inhabitants with $49.3 \%$ of women living in West Java (the Statistic of West Java, 2017). The concern is that approximately $0.5 \%$ of women have received a diagnosis of breast cancer, and it is predicted that $9.6 \%$ of young women in West Java are at risk of developing breast cancer. During the year of study commenced, 2014-2018 in the Hasan Sadikin General Hospital with a 900-bed capacity, which is the top referral location for breast cancer in the province, 10,170 women sought treatments for cancer and 913 
(10\%) of this group sought treatments for breast cancer (Hasan Sadikin General Hospital Information System) [2].

Since West Java and DKI Jakarta provinces share the borders, the two cancer registries regularly exchange records of cancer patients who move across the border for treatment. In the population-based cancer registration, such cases were registered only in the province of the first diagnosis. The number of undetected cases is difficult to estimate due to access to remote villages especially in the mountainous areas with limited access to health facilities, but it is expected to be low. Female breast cancer cases were extracted from the registry database from 2014 to 2018 using ICD-10 codes C50.X. The information included the age and date of diagnosis [2].

This study aims to report and analyze the basic facts about breast cancer in West Java Indonesia from 2014 to 2018.

\section{METHODS}

\section{Data Sources}

The data was collected from the medical records deposited in the Hasan Sadikin General Hospital Information System. The team has been contracted to operate the registry \& organize an advisory board to standardize definitions of terminology coding of the registry's reporting system and to monitor the cancer care pattern. The data, such as an address, age at diagnosis, histopathology type, immunohistochemistry results, stage, and type of surgery validation, were validated by a team in the cancer registry, consisting of health officers, pathologists, and registrars. We used the system information software of Hasan Sadikin General Hospital and the medical records of the Department of Anatomical Pathology. A team has been appointed to perform registry and organize an advisory board to standardize coding definitions as well as to monitor the cancer care pattern. Data validation was conducted by a team in the cancer registry, consisting of health officers, pathologists, and registrars. Data management and analysis were conducted by the cancer registry team. This research was ethically approved by The Health Research Ethics Committee of Faculty of Medicine Universitas Padjadjaran No 1075/ UN 6.c.1.3.2/ KPEK/PN/2016.

\section{Statistical Analysis}

We analyzed the basic demographical data, stages, biological markers, histopathology, and various managements of breast cancer in West Java. All data are shown in frequency and percentage.

\section{RESULTS}

\section{Basic Findings of Breast Cancer in West Java}

West Java is a province of Indonesia on the western part of the island of Java. The province has been subdivided into 9 cities and 17 regencies. Based on our data, the total number of breast cancer cases from 2014 to 2018 is 913, as shown in Table 1.

Table 1. Breast cancer incidence distribution in West Java, Indonesia

\begin{tabular}{lrc}
\hline Regency/City & $\mathbf{n}$ & \multicolumn{1}{c}{$\%$} \\
\hline Kabupaten Bogor & 5 & $0.5 \%$ \\
Kabupaten Sukabumi & 84 & $9.2 \%$ \\
Kabupaten Cianjur & 25 & $2.7 \%$ \\
Kabupaten Bandung & 16 & $1.7 \%$ \\
Kabupaten Tasikmalaya & 5 & $0.5 \%$ \\
Kabupaten Ciamis & 7 & $0.8 \%$ \\
Kabupaten Kuningan & 109 & $11.9 \%$ \\
Kabupaten Cirebon & 38 & $4.2 \%$ \\
Kabupaten Majalengka & 2 & $0.2 \%$ \\
Kabupaten Sumedang & 106 & $9.7 \%$ \\
Kabupaten Indramayu & 201 & $22.0 \%$ \\
Kabupaten Subang & 13 & $1.4 \%$ \\
Kabupaten Purwakarta & 9 & $1 \%$ \\
Kabupaten Karawang & 71 & $7.8 \%$ \\
Kabupaten Bekasi & 20 & $2.1 \%$ \\
Kabupaten Bandung Barat & 14 & $1.5 \%$ \\
Kabupaten Pangandaran & 15 & $1.6 \%$ \\
Kota Bogor & 0 & $0.0 \%$ \\
Kota Sukabumi & 5 & $0.5 \%$ \\
Kota Bandung & 115 & $12.0 \%$ \\
Kota Cirebon & 5 & $0.8 \%$ \\
Kota Bekasi & $5.2 \%$ \\
Kota Depok Cimahi & 5 ata Tasikmalaya & $11 \%$ \\
\hline & 5 & \\
\hline
\end{tabular}

\section{Incidence by Age}

The analyses of the survey and registry data showed equivalent results in the age distribution of diagnosed patients. The median data at diagnosis was 49.5 (49.5 \pm 10.6 ) years with the average patient age on the initial diagnosis was $42(42.4 \pm 18.6)$ years. $59.6 \%$ of them are middle-school graduates, $60 \%$ live in a rural area, $40 \%$ have low income, and most of them use Sundanese to communicate (Table 2 ). 


\section{Staging and Surgery}

The presentation stage of breast cancer varies widely throughout Indonesia. In less developed regions, the late-stage presentation is very common. More than half of breast cancer patients present with stage III-IV. The West Java study showed that only $2 \%$ of patients were diagnosed at an early stage, $21.5 \%$ at stage II, $48.2 \%$ at stage III, and $16.3 \%$ at stage IV. The proportion of stage IV patients in this study was likely underestimated as the presenting stage of the disease is generally kept within surgical databases, which do not keep records of stage IV presentations (Table 3 ).

The information about surgical methods was obtained from the medical record. Among 913 patients, mastectomy was the most frequently performed, followed by breast-conserving therapy (BCT), and others (Table 4).

Table 2. Demographic characteristics of breast cancer in West Java

\begin{tabular}{|c|c|}
\hline Variable & Number of patients (\%) \\
\hline Mean \pm std & $49.5 \pm 10.6$ \\
\hline Median & $49.0(19.0-80.0)$ \\
\hline \multicolumn{2}{|l|}{ Age Category } \\
\hline$<20$ years old & $5(0.5 \%)$ \\
\hline $20-29$ years old & $15(1.6 \%)$ \\
\hline $30-39$ years old & $120(13.1 \%)$ \\
\hline $40-9$ years old & $327(35.8 \%)$ \\
\hline $50-59$ years old & 299 (32.8\%) \\
\hline $60-69$ years old & $116(12.7 \%)$ \\
\hline $70-9$ years old & $28(3.1 \%)$ \\
\hline$>80$ years old & $4(0.4 \%)$ \\
\hline \multicolumn{2}{|l|}{ Initially diagnosed } \\
\hline Mean \pm Std & $42.4 \pm 18.6$ \\
\hline Median & 46.0 \\
\hline Range (min-max) & $19.0-80.0$ \\
\hline \multicolumn{2}{|l|}{ Residence } \\
\hline Rural & $548(60.0 \%)$ \\
\hline Urban & $365(40.0 \%)$ \\
\hline \multicolumn{2}{|l|}{ Level of Education } \\
\hline Primary school and below & $186(20.4 \%)$ \\
\hline Middle & $544(59.6 \%)$ \\
\hline High & $183(20.0 \%)$ \\
\hline \multicolumn{2}{|l|}{ Income/month } \\
\hline Low (<2 million IDR) & 366 (40.0\%) \\
\hline Middle (2-4 million IDR) & 319 (34.9\%) \\
\hline High (above 4 million IDR) & $228(25.1 \%)$ \\
\hline \multicolumn{2}{|l|}{ Language } \\
\hline Indonesian & 429 (47.0\%) \\
\hline Sundanese & 484 (53.0\%) \\
\hline
\end{tabular}

Table 3. Stage distribution of newly diagnosed breast cancer patients

\begin{tabular}{lc}
\hline Group & No. Patients (\%) \\
\hline Stage 0 & $2(0.2 \%)$ \\
Stage I & $16(1.8 \%)$ \\
Stage II & $196(21.5 \%)$ \\
Stage III & $440(48.2 \%)$ \\
Stage IV & $149(16.3 \%)$ \\
Undefined & $110(12.0 \%)$ \\
\hline Total & $\mathbf{9 1 3 ( 1 0 0 \% )}$ \\
\hline
\end{tabular}

Table 4. Surgical management of newly diagnosed breast cancer patient

\begin{tabular}{lc}
\hline Group & No. of patients (\%) \\
\hline Lumpectomy & $26(2.8 \%)$ \\
Breast-Conserving Therapy & $27(3.0 \%)$ \\
Mastectomy & $254(27.8 \%)$ \\
Palliative Mastectomy & $432(47.3 \%)$ \\
Biopsy only & $174(19.1 \%)$ \\
\hline Total & $\mathbf{9 1 3}(\mathbf{1 0 0 \% )}$ \\
\hline
\end{tabular}

\section{Pathology and Biological Markers}

The 913 patients with pathologic results were reported on the online registry. Invasive ductal carcinoma of no special type (NST) cases was the most common histopathology type with 422 cases or $46.2 \%$, followed by invasive lobular carcinoma, ductal carcinoma in Situ (DCIS), other special type carcinoma, and unclassified histopathology types by 77 (8.4\%), 16 (1.8\%), 65 (7.1\%), and 333 (36.5\%) cases respectively as shown in Table 5.

Table 5. Histopathology types

\begin{tabular}{ll}
\hline Histopathology Types & No. of patients (\%) \\
\hline $\begin{array}{l}\text { Invasive carcinoma of no special } \\
\text { type (NST) }\end{array}$ & $422(46.2 \%)$ \\
Invasive lobular carcinoma & $77(8.4 \%)$ \\
Ductal Carcinoma Insitu (DCIS) & $16(1.8 \%)$ \\
Special type carcinoma & $65(7.1 \%)$ \\
No Data & $333(36.5 \%)$ \\
\hline Total & $\mathbf{9 1 3 ( 1 0 0 \% )}$ \\
\hline
\end{tabular}

The proportion of patients with tumors positive for Positive Hormonal Receptor was 22.1\%. The Her2-neu2 expression and triple-negative immunohistochemical (IHC) staining were identified by $7.1 \%$ and $8.7 \%$ respectively, while other patients without the information of immunohistochemistry results were accounted for $55.8 \%$ (Table 6). 
Table 6. Biological markers

\begin{tabular}{lc}
\hline Variable & Number of patients (\%) \\
\hline Her2neu & $65(7.1 \%)$ \\
Luminal & $71(7.8 \%)$ \\
Luminal A & $44(4.8 \%)$ \\
Luminal B & $78(8.5 \%)$ \\
Luminal-Her2 & $67(7.3 \%)$ \\
Triple-Negative & $79(8.7 \%)$ \\
No Data & $509(55.8 \%)$ \\
\hline
\end{tabular}

\section{DISCUSSION}

We describe the basic facts of the breast cancer in West Java Indonesia and analyze the cancer incidence trends using Canreg 5 registry and national survey data. The West Java Cancer Registry is part of the national registry system that was initiated in 2014 and the online registration program that was established in 2014 . The nationwide registry data was used as the foundation of our annual report, completed by various research studies. The hospital data of 913 women patients with breast cancer represented $89.9 \%$ of West Java Health Registry data. The data cannot be compared with the National Cancer Registry because it was not published yet.

We found that age is one of the most important risk factors for breast cancer. It is a common observation that breast cancer risk increases with age. The median age of 49 in Indonesian patients is much lower than that of in American population at 62 years [1]. The woman mean age with breast cancer in the study is 49.5 years, which is younger than in other developing countries and a decade earlier than western women. In Asian countries, the age at diagnosis of breast cancer is substantially lower than in higher-income countries with a median of 53.9 years in Japan, 51 years in Korea, 48-50 years in China, and 48.3 years in Thailand [3-5].

Globally, one in three women or about $33 \%$ were diagnosed with breast cancer and estimated at under 50 at the time of diagnosis. It is lower if compared with those in the Asia-Pacific region and the subregion of Southeast Asia accounted for $42 \%$ and $47 \%$, respectively. A peak in the age-specific incidence rates occurred in Australian women at 50-69 years old, coinciding with the target age range for screening. Incidence rates in the Philippines continued to increase with advancing age $[6,7]$. In contrast, our data show that the peak in age-specific incidence rates happens at the age of 42.4 years. The peak age of breast cancer is younger in Asia. It is predicted that there is variation in tumor biology of women diagnosed with breast cancer. As a consequence, the treatment recommendation of these patients may vary aiming to improve survival rates [8].
The surveyed patients mostly have middle-school education background (59.6\%), live in the rural area (60.0\%), have low income (40.0\%), and speak Sundanese for daily communication. In the previous study by Anwar et al. [9], it was revealed that sociodemographic determinants, such as family socioeconomic status, ethnicity, rural residence, health expenditure, and healthcare access, are associated with breast cancer screening participation and should be considered and designed to improve breast cancer management. Further, some parts of West Java are rural areas and are far from health facilities with difficult access to get health information and health services. As for the education gap, the culture of the community, in which all decisions are very dependent on the elders, is also to be considered in providing counseling from different perspectives in breast cancer management. Sundanese, which is the main local language in West Java, is also an aspect that must be considered to establish communication with the community.

Across Asia, the data on the stage at presentation also reflects regional, ethnic, and socioeconomic disparities. Many breast cancer patients in Indonesia, also similarly presented in West Java cases, came up with the late stage, which consisted of Stage III (48.2\%) and Stage IV (14.1\%). This may not the real number due to missing information by $12.0 \%$ of our population. We conducted a current multicenter study to extensively analyze factors affecting the rate on a higher stage in Indonesia. High breast cancer mortality in West Java, Indonesia in general, is mostly attributable to late-stage disease presentation, which leads to the particularly poor outcome when combined with limited capacity for the accurate diagnosis and adequate therapy. Building public awareness of using complementary alternative medicine (CAM) for improving breast cancer outcomes is not always appropriate and is also the main cause of these women being late to the hospital. Most patients with lower income and lower education are usually afraid of seeking conventional treatments due to the lack of knowledge and prefer to use CAM as the main therapy. They usually use conventional therapy if the use of CAM is unsuccessful [10].

Similarly, in Thailand, $17 \%$ of patients reported a delay in medical consultation, and $42 \%$ saw the doctor for more than 3 months after the diagnosis. Family income, education, previous breast symptoms, selftreatment, and travel time to the hospital are associated with a delay in treatment initiation. Release and provision of more updated research priorities to all related institutes by the Council of Cancer Control define a unique center that is responsible to register projects focusing on breast cancer control [11].

In China, the median time delay for treatment is 1 month in wealthy areas, compared to 94 days in lessdeveloped western and central regions. In some 
undeveloped regions of China, delays of more than 1 year occurred on $12-17 \%$ of patients. These numbers lead to a concern on the efforts to increase awareness and early diagnosis of breast cancer [11]

In Indonesia, the treatment often does not concur with current international guidelines. The most common intervention for breast cancer, mastectomy, can be done in a technically suboptimum manner in which inexperienced surgeons can leave significant and resectable malignant tissue in the mastectomy and axillary beds. There are some cases that the cancer patients were referred back to the hospital to be reoperated for the optimum result by conducting axillary or residual disease clearance. Although cobalt radiotherapy is regarded outdated in high-resources countries, it remains an important therapy in Indonesia setting, especially to those having poor infrastructure, physics main power and maintenance facilities, and inconsistent and unreliable sources of electricity and water that are needed to operate linear accelerator units.

The absence of advanced pathology services to establish hormone-receptor status continues to obstruct appropriate decision-making for endocrine therapy. The distribution variation of hormonal receptors in Indonesia is different from other countries, for example, Malaysia, due to a lack of $55.8 \%$ data. The safe administration of systemic chemotherapy, which is crucial to improve breast cancer outcomes for ER-negative and nodepositive cancers, needs the availability of drugs, infrastructure for drug administration, and well-trained physicians and non-physician staffs [12].

Unlike Ghana, Indonesia has a formal in-country certification process for medical oncology and surgical oncologist, but the distribution of this specialty is still minimum, which leads to exceeding cancer health care budgets in Indonesia [13]. Supportive care, which broadly includes side-effect treatment, palliative care, and end-of-life care, is an emerging specialty in West Java in cases where attention to the treatment of sideeffects and care of advanced breast cancer was neglected and where morphine availability for patients is highly problematic. This complex situation causes the treatment of breast cancer more expensive and burdensome for the national insurance health system. Efforts to control risk factors are advised, such as activating healthy community movements by avoiding fatty foods and increasing regular exercise. Besides, it is important to evaluate counseling and early detection methods that have been carried out for a better result. The government and other professional organizations also need to standardize breast cancer management in every region by providing adequate facilities and organizing refresher courses.
Lastly, this study has limitations and rely on quantitative data from one tertiary hospital in West Java. It is necessary to further conduct quantitative and qualitative analyzes of social demographic factors to improve breast cancer management. Although our data is not ideal for epidemiologically standardized purposes, it can be used to practically manage breast cancer in West Java.

\section{CONCLUSIONS}

Breast cancer in West Java Indonesia is often recognized at the late stage. The treatment was suboptimal, leading to poor survival. A more aggressive approach to early detection and treatment need to be developed to improve the outcome of this potentially curable disease.

\section{DECLARATIONS}

\section{Competing of Interest}

The authors declare no potential conflicts of interest.

\section{Acknowledgment}

We thank all members of the Regional Cancer Registry Team West Java for collecting and providing data.

\section{REFERENCES}

1. Ferlay J, Soerjomataram I, Ervik M, Dikshit R, Eser S, Mathers C, et al. GLOBOCAN 2012: Estimated cancer Incidence, mortality, and prevalence worldwide in 2012: Int J Cancer. 2012;136:E359-86.

2. Dinas Kesehatan Provinsi Jawa Barat. Profil Kesehatan Jawa Barat 2017 [Internet]. [Accessed April 10th, 2020]. Available from http://www.diskes.jabarprov. go.id.

3. Kim Z, Min SY, Yoon CS, Won Jung K, Seok Ko B, Kang $E$, et al. The basic facts of korean breast cancer in 2012: Results from a nationwide survey and breast cancer registry database. J Breast Cancer. 2015;18(2): 103-11.

4. Fan L, Zheng Y, Yu KD, Liu GY, Wu J, Lu JS, et al. Breast Cancer in a transitional society over 18 years: Trends and present status in Shanghai, China. Breast Cancer Res Treat. 2009;117(2):409-16.

5. Youlden DR, Cramb SM, Yip YH, Baade PD. Incidence and mortality of female breast cancer in the AsiaPacific region. Cancer Biol Med. 2014;11(2):101-15. 
6. Youlden DR, Cramb SM, Dunn NA, Muller JM, Pyke CM, Baade PD. The descriptive epidemiology of female breast cancer: An international comparison of screening, incidence, survival and mortality. Cancer Epidemiol. 2012;36(3):237-48.

7. Bray F, Ferlay J, Soerjomataram IS, Siegel RL, Torre LA, Jematistics, et al. Global cancer statistics 2018: GLOBOCAN estimates of incidence and mortality worldwide for 36 Cancers in 185 countries. CA Cancer J Clin. 2018;68(6):394-424.

8. Wong FW, Tham WY, Nei WL, Lim C, Miao H. Age exert a continuous effect in the outcomes of Asian breast cancer patients treated with breast-conserving therapy. Cancer Commun. 2018;38(1):39.

9. Azhar Y, Dimyati A, Lukman K, Hilman D, Aryandono T. Predictor of complementary and alternative medicine use by breast cancer patients in Bandung, Indonesia. Asian Pac J Cancer Prev.2016;17(4):2115-8.
10. Anwar SL, Tampubolon G, Hemelrijvk MV, Hutajulu $\mathrm{SH}$, Watkins J, Wulaningsih $\mathrm{W}$, et al. Determinants of cancer screening awareness and participation among Indonesian Women. BMC Cancer. 2018;18(1):208.

11. Poum A, Promthet S, Duffy SW, Parkin DM. Factors Associated with Delayed Diagnosis of Breast Cancer in Northeast Thailand. J epidemiol. 2014;24(2):102-8.

12. Mardela AP, Maneewat K, Sangchan H. Breast cancer awareness among Indonesian women at moderateto-high risk. Nurs Health Sci. 2017;19(3):301-6.

13. Clegg-Lamptey J, Hodasi W. A study of breast cancer in Korle Bu Teaching Hospital: Assessing the impact of health education. Ghana Med J. 2007;41(2):72-7. 